\title{
Correspondence
}

TO THE EDITOR OF THE Journal

\section{LARGE SHIP RADAR}

Dear Sir,-In my article on large ship radar, which you published in the October issue of the Journal, I quite inadvertently made no acknowledgment of the help I had received in compiling the data. I would like now to express my apologies for the omission and my grateful thanks for the very considerable assistance I received from Associated Electrical Industries, Ltd., Decca Radar Ltd., Kelvin Hughes Ltd., the Marconi International Marine Communication Co. Ltd., the Radio Corporation of America, the Raytheon Company and the Sperry Gyroscope Company of America.

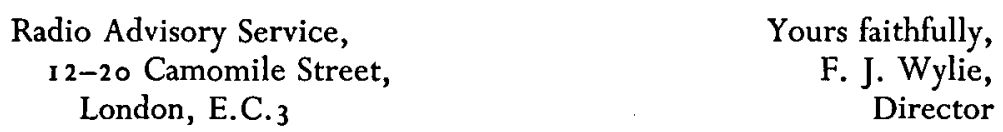

